\title{
Cardiocutaneous fistula
}

\author{
P G Danias, T Lehman, T Kartis, J C Missri
}

\begin{abstract}
Infection of the Teflon pledgets on the heart suture line after left ventricular aneurysm repair, presenting late with a fistulous tract connecting the heart with the skin (cardiocutaneous fistula) is an uncommon but potentially serious condition. The case is reported of a 73 year old man who developed a cardiocutaneous fistula extending through the left hemidiaphragm and draining at the abdominal wall, which developed six years after left ventricular aneurysmectomy. Following radiographic evaluation, which established the diagnosis, the Teflon pledgets and fistulous tract were successfully surgically removed. Prompt diagnosis depends on a high index of suspicion. Eradication of infection requires excision of infected material, which must be planned on an individual basis.

(Heart 1999;81:325-326)
\end{abstract}

Keywords: cardiocutaneous fistula; Teflon pledgets; suture line; aneurysm

Delayed infection of the suture line after left ventricular aneurysm repair is an uncommon but potentially serious surgical complication, ${ }^{12}$ which occurs when Teflon pledgets are used to reinforce the myocardial suture line. The infection can either spread locally or cause bacteraemia and sepsis. With local extension, a fistulous tract can form and exit either at the bronchial tree (cardiobronchial fistula) or through the chest wall and skin (cardiocutaneous fistula). We present a patient who developed a cardiocutaneous fistula extending through the left hemidiaphragm and draining at the abdominal wall six years after left ventricular aneurysmectomy. The relevant literature is also reviewed.

\section{Case report}

A 73 year old man had coronary artery bypass surgery and left aneurysmectomy following an extensive anterior wall myocardial infarction in July 1990. In February 1996, he developed a painless $2 \times 2 \mathrm{~cm}$ area of skin induration and erythema at the left upper abdominal quadrant, below the rib cage, and lateral to the scar of the chest tube from the previous cardiac surgery. This area subsequently developed purulent drainage. The patient denied fever or other systemic symptoms and was treated with oral antibiotics for a presumed skin infection. The

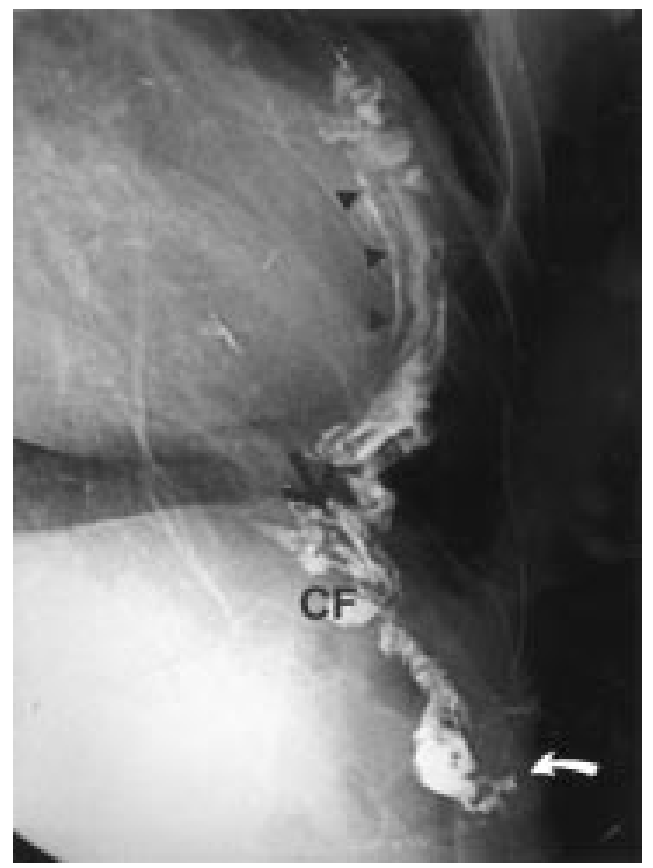

Figure 1 Following retrograde contrast fistula injection, the course and extent of the fistulous tract can be seen. The cardiocutaneous fistula (CF) originated from the left ventricle at the aneurysm repair site (black arrowheads) extended through the left hemidiaphragm (black arrow) and exited at the abdominal wall (white curved arrow).

purulent drainage persisted and prompted radiological work up with contrast retrograde fistula injection. A long fistulous tract was seen originating from the myocardium, extending through the diaphragm, and exiting at the abdominal wall (fig 1). A bone scan excluded osteomyelitis of the ribs. Echocardiography and cardiac catheterisation in April 1996, during hospitalisation for unstable angina, failed to identify the paracardiac process. Surgical exploration and successful removal of the fistulous tract was performed electively in June 1996. Surgical approach was through both lateral thoracic and abdominal incisions and did not require cardiopulmonary bypass. Part of the adjacent seventh rib was also removed to allow thorough excision of the inflamed tissue. After removal of the Teflon pledgets, the thickened pericardium was used to reinforce the myocardial suture line. Microscopic examination of the removed tissue revealed focal histiocytic and giant cell inflammatory reaction. Gram stain showed $<10$ neutrophils/high power field, and prolonged cultures for aerobic 
and anaerobic bacteria, fungi, and acid fast bacilli were all negative.

Following surgery the patient recovered well and had no recurrence of site infection during 15 months of follow up. Mild persisting local chest wall pleuritic discomfort was attributed to insicional intercostal neuropathy and was treated with oral analgesics.

\section{Discussion}

Infection of the suture line after left ventricular aneurysm repair is a rare but potentially serious complication. Thirty one cases $(28 \mathrm{men})$ of suture line infections following cardiac surgery have been reported. ${ }^{1-5}$ Of these, 18 were true cardiocutaneous fistulae draining at the chest wall, six presented as bacteraemia alone, and the remaining seven were cardiobronchial fistulae. The mean time to presentation was 16 months from the original surgery with a wide range ( 0.5 to 84 months). Although microorganisms with low virulence (Staphylococcus epidermidis, Peptostreptococcus sp, etc) are commonly isolated, more aggressive pathogens (such as Staphylococcus aureus) have also been reported. ${ }^{2}$ Sterile inflammatory reaction resulting in fistula formation and secondary colonisation has also been suggested. ${ }^{6}$

Diagnosis is usually delayed because of the chronicity and indolent characteristics of the infection. Computed tomography and magnetic resonance imaging have high diagnostic yield. Retrograde contrast fistula injection allows visualisation of the course and extension of the fistulous tract. Other imaging tests (angiography, echocardiography) can also be helpful in establishing the diagnosis.

Management of cardiocutaneous fistulae requires surgical excision of the tract and removal of the infected foreign bodies (usually Teflon pledgets)..$^{3-5} 7$ Oral antimicrobial treatment will not eradicate the infection. Removal of the myocardial pledgets after aneurysmectomy is relatively safe, especially if this is done long after the original operation. The surgical procedure should be individualised to allow complete excision and adequate reinforcement of the suture line, and cardiopulmonary bypass is not always necessary.

Associated mortality of cardiocutaneous fistulae is high: six of the 32 reported patients died; in four, reoperation was not performed. Strategies to prevent infection of the suture line include meticulous technique and use of absorbable materials or autologous pericardium to bolster the suture line at the time of the initial surgery. ${ }^{8-10}$

In summary, delayed infection of the suture line involving the Teflon pledgets used for left ventricular aneurysm repair is an uncommon but serious complication. A high index of suspicion and prompt diagnostic evaluation with the appropriate imaging tests are required. Removal of the pledgets and the fistulous tract is indicated.

1 Looser KG, Allmendinger PD, Takata $\mathrm{H}$, et al. Infection of cardiac suture line after ventricular aneurysmectomy. Report of two cases. $\mathcal{f}$ Thorac Cardiovasc Surg 1976;72:280-1.

2 McHenry MC, Longsworth DL, Rehm SI, et al. Infections of the cardiac suture line after left ventricular surgery. $A m \mathcal{F}$ Med 1988;85:292-300.

3 Wellens F, Vanermen H. Treatment of the infected cardiac suture line. F Card Surg 1988;3:109-18.

4 McCormick JR, Berger RL, Davis Z. Management of cardiocutaneous fistulas [letter]. $\mathcal{F}$ Thorac Cardiovasc Surg 1981;81:317-18.

5 Chatzis A, Pepper J, Treasure T. Infected intraventricular teflon patch: repair and closure of fistula with omentum. $\mathrm{Br}$ teflon patch: repair and

6 Deuvaert FE, Wellens F, De Paepe J, et al. Cardiocutaneous fistula after left ventricular aneurysm repair. Case report and review of the literature. F Cardiovasc Surg 1984;25: 560-3.

7 Stanford W, Reuben CF, Flemma RJ, et al. Management of long-standing cardiocutaneous fistulas after resection of left ventricular aneurysms. F Thorac Cardiovasc Surg 1980; 79:789-92.

8 Vincent JG, Skotnicki SH, van der Meer JJ, et al. Resorbable suture support for ventricular aneurysmectomy. F Thorac Cardiovasc Surg 1987;94:430-3.

9 Fiore AC, McKeown PP, Misbach GA, et al. The use of autologous pericardium for ventricular aneurysm closure. autologous pericardium for ventricu
Ann Thorac Surg 1988;45:570-1.

10 Liotta DS, Frank LG. Routine application of the omental pedicle graft. Tex Heart Inst F 1991;18:8-12. 